\title{
Research on the Construction of Teaching Staff in Application-Oriented Universities
}

\author{
Xingzhi Zhou, Wenjing Lei \\ Human Resources Office, Xi'an Aeronautical University, Xi'an, China \\ Email: rzkj1980@163.com
}

How to cite this paper: Zhou, X.Z. and Lei, W.J. (2018) Research on the Construction of Teaching Staff in Application-Oriented Universities. Open Journal of Social Sciences, 6, 286-292.

https://doi.org/10.4236/jss.2018.612025

Received: December 5, 2018

Accepted: December 26, 2018

Published: December 29, 2018

Copyright $\odot 2018$ by authors and Scientific Research Publishing Inc. This work is licensed under the Creative Commons Attribution International License (CC BY 4.0).

http://creativecommons.org/licenses/by/4.0/

\begin{abstract}
With the rapid development of science and technology in China, our country is in urgent need of many application-oriented technical personnel with high academic degrees, which promotes the construction of application-oriented universities in China. It is necessary to accelerate the construction of application-oriented university teachers in order to promote the quality of universities better. The construction measures of application-oriented university teachers are studied and analyzed in this paper.
\end{abstract}

\section{Keywords}

Application-Oriented, University Teachers, Team Building

\section{Introduction}

Higher education plays an important role in economic growth and social progress. The development level of higher education and the quality of talent cultivating all depend on the quality of teachers to a great extent. Application-oriented university is a kind of universities which aim at training high-level application-oriented students. With the high-quality development of economy in China, the demand of talents in high-tech industries is very heavy in the process of social progress and development. As an educational institution for training high-quality professional talents, they need to improve the educational strengths of the teachers' teams constantly, so as to provide high-quality and high-capacity professional talents to the society.

\section{Analysis on the Construction Situation of Teachers' Team of Application-Oriented Universities in China at Present}

Under the promotion of the development of social economy in our country, not 
only all industries have entered into a comprehensive upgrade process, but also the university education policy appeared certain adjustment. In order to cultivate more professional high-ability talents, many universities have begun the transformation in teaching style. They start to adjust the teaching plan according to the change of the social development to achieve the ultimate goal of national development. For teaching methods, we have already improved the content of textbooks, adjusted the allocation of teachers and strengthened the teaching of students' employment instruction. Teachers are required to obtain instructor (or above) professional title and corresponding professional title or qualification certificate of the related work for the majors at applied-oriented universities. Therefore, it can be seen that vocational and technical teachers are needed for the transformation.

In the process of application-oriented universities transformation, a serious problem has arisen, that is, the serious shortage of vocational and technical teachers, which has certain impact on the development of educational programs in application-oriented universities. Therefore, it is urgent to build a group of teachers with comprehensive teaching ability and practical work guidance ability in the current social development environment. Many universities in our country are in the stage of transformation and exploration, that is to say, there is not much experience to refer to, we can only feel the stones across the river, groping for the development plan of building application-oriented universities slowly [1].

The main teaching goal of application-oriented universities is to train a group of applied students with professional competence in undergraduate universities. In the process of conventional theoretical teaching, some exploratory research projects need to be carried out in time. Due to the particularity of application-oriented universities, the teachers also need to have special teaching ability. From the perspective of undergraduate cultural knowledge teaching, application-oriented teachers need not only excellent professional teaching ability, but also certain degree of practice guidance ability on employment. That is to say, teachers need the ability to solve practical problems, so as to give students the most direct, effective graduation guidance.

\section{Analysis on the Construction of Teachers' Team in Application-Oriented Universities}

In the process of building an application-oriented teaching staff in universities, the scope of education is limit in their own universities in the process of teacher management, which has led to difficulties in introducing outstanding talents from outside. With the continuous accelerating construction of universities in China, the increasing number of students has brought great pressure to the teaching in universities. Therefore, it is necessary to improve the abilities of all teachers, expand the talent introduction management system and employ new talents into teachers' teams. 
There is also a prominent problem in the process of teachers' management in universities, that is, the structure of teachers' professional titles is unreasonable. A large number of teachers with senior professional titles are needed in the process of developing application-oriented universities, while there are fewer teachers with senior professional titles in many undergraduate universities, thus it affects the development of application-oriented teaching plans. In 2004, ministry of education issued the Talent Cultivation Work Level Assessment Program for Higher Vocational and Technical Colleges (test), which required that the proportion of qualified and excellent vocational and technical teachers are 50\% and $70 \%$ respectively. It provides policy basis for the construction of vocational and technical teachers in applied-oriented universities, which also reflects the shortage of vocational and technical teachers in applied-oriented universities.

In the process of transformation on applied education in universities, some young teachers with practical application ability are needed, but these resources are lacking in universities. Some teachers with many years of professional theory teaching have no problems in teaching, but in the teaching process of actual employment guidance, they are unable to achieve the teaching requirements well. It fails to achieve the professional practice teaching goals formulated by the Ministry of Education.

\section{Analysis on the Construction Direction of Teachers' Team in Application-Oriented Universities}

\subsection{Reforming the Structure of Teachers' Team}

In the process of the construction of application-oriented teaching team in universities, in order to improve the abilities of teaching staff, it is necessary to introduce teaching staff from all over the world and collocate the teaching staff scientifically, so as to enhance the educational level of the teaching staff continuously and create a professional vocational and technical teaching team. In the process of the construction of application-oriented teachers' team, in order to relieve the teaching pressure of teachers, we can reasonably build a part-time teaching team related to teaching specialty according to the actual teaching situation. We can also hire some experienced senior engineers from front-line scientific research institutions. Its main purpose is to improve students' professional practice ability, so as to improve students' employment practice ability. In order to build a better application-oriented teaching environment on campus, academic professors and research frontiers of corresponding majors can come to universities to carry out academic lectures, which is of great help to enhance the teaching abilities of university teachers. In the process of building application-oriented teachers' team, for reserving excellent educational talents reasonably, university teachers can compete in teaching spontaneously and teach in other universities as talents, so as to exert the full abilities of teachers [2]. Therefore, the reformed teachers' team is composed of vocational and technical teachers, part-time teachers from enterprises and professional teachers for basic 
knowledge teaching.

\subsection{Improving the Training System of Teachers}

In the process of transformation of application-oriented education in universities, in order to improve teachers' teaching ability, it is necessary to enhance teachers' training system and improve teachers' innovative teaching ability. In the procedure of perfecting and optimizing the actual training system, we can give young teachers the learning process of going abroad for further study, enterprise practice, education improvement and classified training, so as to improve the vocational and technical teaching ability of young teachers continuously.

In the process of carrying out the training plan for young teachers, we need to use relevant policies to support and encourage them, so that young teachers can improve their teaching ability independently, and cultivate high-quality applied undergraduate talents constantly. In the process of training, we can also improve the teaching ability of university teachers through communication between teachers, teachers' research and academic exchange activities at home and abroad. In order to ensure that the group of teachers have strong abilities of professional teaching and career guidance, universities can introduce some teachers to enterprises for duty study and practice according to the school's strategic plan. The main reason is to broaden teachers' horizon, so that they keep up with the times. With the development of economy, after a period of practical learning in enterprises, the comprehensive teaching ability of teachers can be improved. After returning to school, the experience of practical learning can be shared with other teachers, which promotes the construction of application-oriented teachers effectively [3].

In the process of training and improving of teachers' quality, a lot of funds are needed, and teachers are sent to enterprises for duty learning, which also requires certain funds. If it depends on the financial expenditure of universities, it cannot be implemented effectively in a long term. Therefore, in the process of building the teaching staff, we can strive for the local government's financial allocation, the university's professional allocation and the funds for scientific research projects, so as to alleviate the financial pressure of universities effectively. Collecting certain tuition fees, accommodation fees and training fees, and taking scientific research results into certain economic benefits can be benefit to the construction of university teachers.

\subsection{Measures for Cultivating Vocational and Technical Teachers}

In the process of building application-oriented teaching staff in universities, for stimulating teachers' motivation of teaching and scientific research, special teaching treatment can be given to teachers who have outstanding teaching ability by introducing professional teaching talents and formulating talent incentive system. In order to avoid the loss of talents in the process of talent management, 
it is necessary to provide strong support in the fields of teachers' professional title, salary, housing treatment, research funds, team formation and system construction. As General Secretary Xi Jinping mentioned at the meeting, we must ban the rules that confine scientists, educators and entrepreneurs, and let them do it boldly and freely so as to achieve the best results. In the process of building the application-oriented teaching staff, teachers should not be restrained. Teachers should dare to think, implement and innovate, so as to improve the teaching abilities continuously.

In order to perfect the talents management and the adjustment of teachers' abilities, it is necessary to establish a perfect performance appraisal and evaluation system. Through the optimization and improvement of the traditional human resources management system of teachers, new educational rules and regulations, teaching posts and personnel guidance should be set up under the new system. In other words, teachers need to be restrained in teaching behavior, and their worries should be solved, so that teachers can devote themselves to professional teaching. Also, it can lay a good foundation for the establishment and improvement of humanized management system of teaching team in universities [4].

In the process of the construction of vocational and technical teachers in universities, it is necessary to optimize the structure of teachers effectively, reform the traditional appointment system and optimize the old evaluation system, so as to improve the professional ability of teachers better. In the procedure of building application-oriented teaching staff, we need to formulate the welfare and salary subsidy of vocational and technical teachers clearly, so that teachers can participate in the application-oriented teaching actively. Under such educational reform environment, the teaching quality of universities can be improved well, and it can output high-skilled professionals to the society.

\subsection{Strengthening the Construction of Teachers' Morality}

The scope of teacher's moral anomie refers to the lack of ideological and moral quality, professional level, work attitude and positive life value. In recent years, there has been a constant outbreak of the incorrect style of teachers in universities, which has seriously affected the construction of teaching staff in universities. Not long ago, foreign media exposed that a Doctor of Tsinghua University has academic misconduct and other acts. Finally, after an in-depth investigation by the Education Department of our country, it was found that the student published several professional papers during his study period, many of which were copied from other people's research results, and there were fake data in the published papers. Falsification and other acts seriously affect the teaching environment of the college, and the student's instructor also has an inescapable responsibility. In the process of students' publishing, there is no careful review, which leads to students' academic fraud. Finally, Tsinghua University cancelled his bachelor's professional titles, and the corresponding tutor was not allowed to 
enroll students because he did not do a good job in the construction of teachers' morality [5].

From the above events, we can find that the construction of teachers' morality is very important. Many undergraduate universities should build high-quality teaching staff in the process of transformation of application-oriented education. The construction of teachers' morality has a direct influence on the development of application-oriented teaching plan. It has certain impact on the quality of universities, and also on students' professional knowledge learning. It has laid a hidden danger to the development of some corresponding industries in society. In order to improve the abilities of the teaching staff, we need to improve the ideological awareness and professional ethics of teachers constantly. In the process of academic research management, we should set a picket line strictly. Once we find that students or teachers have academic misconduct, we should deal with it strictly. Meanwhile, we should deepen the construction of atmosphere of teachers' morality so as to form an educational environment of loving posts, devoting ourselves to work, rigorous scholarship and respecting talents in universities. Therefore, the construction process of teaching staff can be carried out constantly, and the students' comprehensive practical learning ability can be enhanced [6].

\section{Conclusion}

In the process of carrying out the development of application-oriented education, in order to build up a group of high-standard teaching staff, we need to improve teachers' introducing system, create part-time teaching system of professional talents, and set up academic exchange conferences at home and abroad, so as to improve the teaching quality of high-level professionals in our universities continuously. For further study, the concrete measures to cultivate teachers still need to be improved. Universities should strengthen relevant training and guidance for teachers, and relevant enterprises should also give full support in constructing teaching staff for applied-oriented universities.

\section{Acknowledgements}

The authors acknowledge the Higher Education Research Fund Project of Xi'an Aeronautical University: Research and Practice of the Cultivation Method of Vocational and Technical Teachers in Application-oriented Colleges and Universities (Number: 2018GJ1003).

\section{Conflicts of Interest}

The authors declare no conflicts of interest regarding the publication of this paper.

\section{References}

[1] Zhang, H.M. (2016) The Construction of Teachers' Team Based on the Cultivation 
of Innovative and Entrepreneurial Application-oriented Talents. Continue Education Research, 4, 21-23.

[2] Xu, S.M. (2016) The Review and System Prospect of the Teaching Staff in the Transformation and Development of Application-Oriented Colleges and Universities. Contemporary Education Sciences, 17, 61-64.

[3] Ying, X. (2015) Construction of "Two-Way and Diversified" Teaching Staff: The Key to the Transformation and Development of Local Undergraduate Universities. Research in Education Development, 3519, 40-46.

[4] Li, Z. and Gao, W.Y. (2017) Research on the Construction of Teaching Staff for Applied Universities. Journal of XIAN Aeronautical University, 3506, 85-89.

[5] Qiu, G.F. and Du, D.L. (2018) The Exploration of the Construction of "Vocational and Technical Teachers" in Application-Oriented Colleges and Universities in the New Era. Journal of Jiaying University, 3601, 79-82.

[6] Wang, J.L. (2017) Problems and Countermeasures for the Development of Application-Oriented College Teachers in China. Education and Vocation, 13, 73-76. 